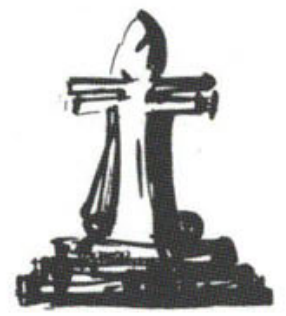






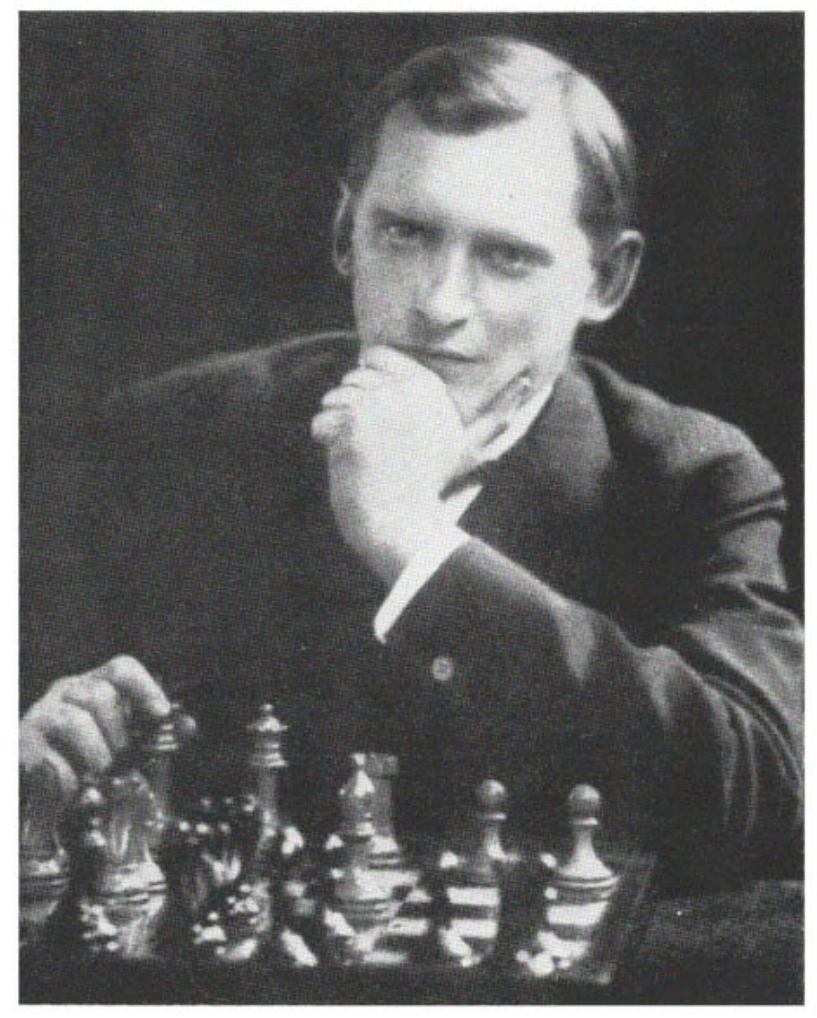

A. ALJECHIN 


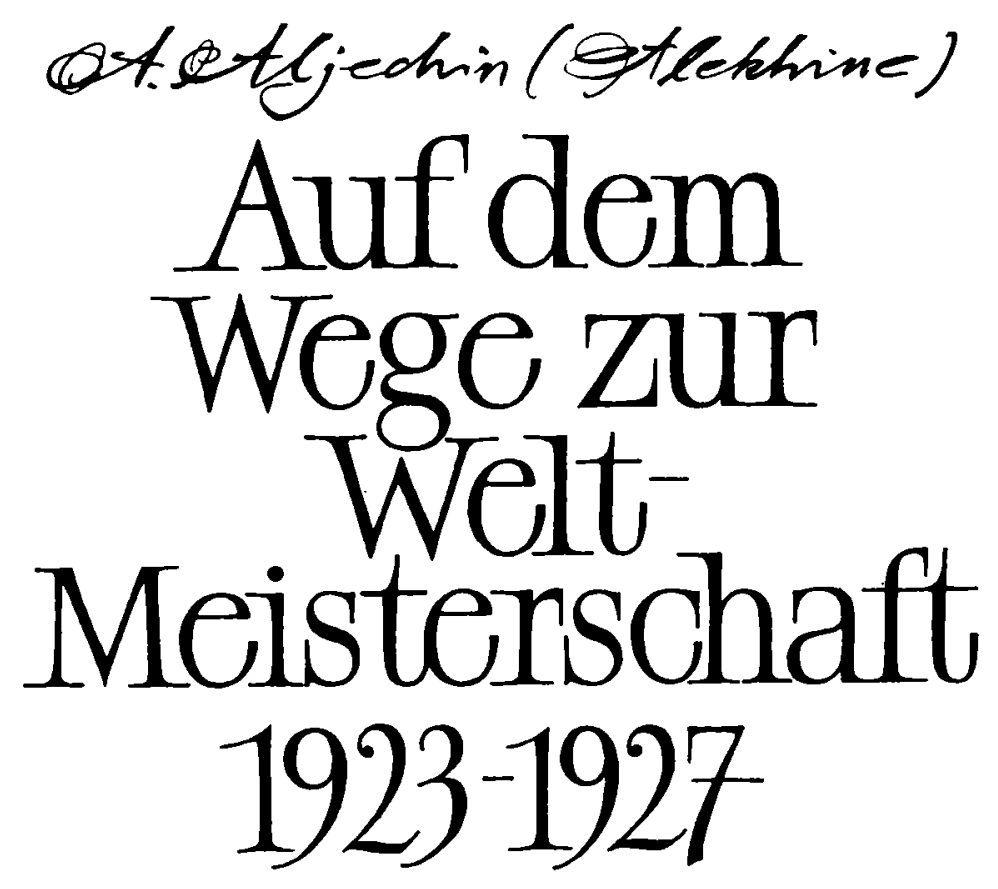

4., durchgesehene Auflage

Mit 100 Partien und 173 Diagrammen

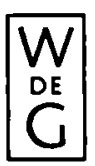

WALTER DE GRUYTER - BERLIN - NEW YORK. 
CIP-Kurztitelaufnahme der Deutachen Bibliothek

\section{Alechin, Aleksandr}

Auf dem Weg zur Weltmeisterschaft : 1923-1927 / A. Aljechin. - 4., durchges. Aufl. - Berlin, New York : de Gruyter, 1978.

Auf d. Haupttitels. auch: Alekhine.

ISBN 3-11-007422-2

(C) Copyright 1977 by Walter de Gruyter \& Co., vormals G. J. Göschen'sche Verlagghandlung, J. Guttentag, Verlagsbuchhandlung Georg Reimer, Karl J. Trübner, Veit \& Comp., Berlin 30.

Alle Rechte, insbesondere das Recht der Vervielfältigung und Verbreitung sowie der Ubersetzung, vorbehalten. Kein Teil des Werkes darf in irgendeiner Form (durch Photokopie, Mikrofilm oder ein anderes Verfahren) ohne schriftliche Genehmigung des Verlages reproduziert oder unter Verwendung elektronischer Systeme verarbeitet, vervielfältigt oder verbreitet werden. Printed in Germany.

Satz und Druck: Walter de Gruyter, Berlin

Bindearbeiten: Franz Spiller, Berlin

Einbandentwurf: Ulrich Hanisch, Berlin 